\title{
Emergência de plântulas de Tabebuia caraiba (Mart.) Bureau
}

\author{
Seedling emergence of Tabebuia caraiba (Mart.) Bureau
}

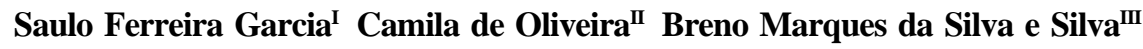

\begin{abstract}
O objetivo da presente pesquisa foi determinar o substrato e a profundidade de semeadura mais adequados para a emergência de plântulas de ipê amarelo. Na avaliação dos substratos, as sementes foram colocadas em caixas de plástico entre areia, solo, resíduos triturados de açaí (endocarpo + semente), vermiculita, serragem, areia + vermiculita (1:1), areia + resíduos triturados de açaí (endocarpo + semente) (1:1), areia + serragem (1:1) e areia + solo (1:1), enquanto, para a profundidade de semeadura, as sementes foram colocadas dentro de caixas de plástico entre areia, nas profundidades de 0,1, 2 e $4 \mathrm{~cm}$ e levadas para casa de vegetação, sendo avaliados, em ambos, a porcentagem e a velocidade de emergência de plântulas. Os substratos mais adequados para emergência de plântulas de ipê amarelo são areia, vermiculita, areia + vermiculita (1:1), areia + solo (1:1) e areia + resíduos triturados de açaí (endocarpo + semente) (1:1). As semeaduras superiores a $1 \mathrm{~cm}$ de profundidade são inadequadas para a emergência de plântulas da referida espécie.
\end{abstract}

Palavras-chave: ipê amarelo do cerrado, substrato, profundidade de semeadura, Bignoniaceae.

\section{ABSTRACT}

The purpose of this research was to determine the substrate and sowing depth for yellow "ipê" seedling emergence. For the emergency, seeds had been used, distributed in plastic boxes, with sand, soil, "açaí" triturate residue (endocarp + seed), vermiculite, sawdust, sand + vermiculite (1:1), sand + "açaí" triturate residue (1:1), sand + sawdust(1:1) and sand +soil (1:1) or in 0, 1, 2 and $4 \mathrm{~cm}$ of sowing depth and kept in greenhouse. The emergency percentage and emergency speed were evaluated for the substrate and sowing depth. The optimum substrate for seedling emergence is sand, vermiculite, sand+vermiculite (1:1), sand + "açaí" triturate residue (1:1) and sand + soil (1:1). Sowing depths higher than $1 \mathrm{~cm}$ are inadequate for yellow "ipê" emergence.

Key words: savanna yellow "ipê", substrate, sowing depth, Bignoniaceae.

Dentre as espécies de ipê, Tabebuia caraiba (Mart.) Bureau, conhecida popularmente como ipê amarelo, pertencente a família Bignoniaceae, é uma árvore nativa ornamental com potencial para a recuperação de áreas degradadas (SOUZA \& LORENZI, 2005). Todavia, as informações básicas sobre a ecologia, biologia e fisiologia de ipê amarelo são incipientes para o auxílio na análise de sementes e produção de mudas.

A renovação da vegetação, recuperação de áreas degradadas, estabelecimento de bancos de germoplasma, programas de melhoramento e plantio para exploração econômica de frutos, madeiras e produtos medicinais são baseados na coleta de sementes e propagação dessas espécies, sendo fundamentais os conhecimentos sobre a dormência e a germinação das

Instituto Macapaense de Ensino Superior (IMMES), Macapá, AP, Brasil.

"Secretaria do Estado da Educação (SEED), Governo do Estado do Amapá (GEA), Macapá, AP, Brasil.

IIIInstituto de Pesquisas Científicas e Tecnológicas do Estado do Amapá (IEPA), GEA, Rod. JK, s/n., Distrito de Fazendinha, 68900-280, Macapá, AP, Brasil. E-mail: silvabms@hotmail.com. Autor para correspondência. 
sementes, assim como a propagação vegetativa das espécies nativas (MELO et al., 2008).

Portanto, o conhecimento sobre a germinação é muito importante, pois há possibilidade de controle e modificação de fatores ambientais para o aumento da germinação e emergência, diminuindo os gastos e obtendo-se assim mudas de qualidade para os mais diversos fins (NASSIF et al., 1998). Dessa forma, para o auxílio na produção de mudas em viveiro, o objetivo no presente trabalho foi determinar o substrato e a profundidade de semeadura adequados para a emergência de plântulas de ipê amarelo.

Os frutos maduros foram colhidos de matrizes de ipê amarelo localizadas no parque natural municipal de Macapá “Arinaldo Gomes Barreto”, em Macapá - AP Brasil, antes da dispersão. Em seguida, foram postos para secar à sombra por 24 horas e depois abertos manualmente para retirada das sementes, as quais foram analisadas no Departamento de Paisagismo e Arborização Urbana Secretaria Municipal de Meio Ambiente - Prefeitura Municipal de Macapá, Macapá - AP.

O teor de água das sementes de ipê amarelo foi determinado por meio da secagem em estufa a $105 \pm 3^{\circ} \mathrm{C}$ por 24 horas, de acordo com Regras de Análise de Sementes (BRASIL, 2009), porém com o uso de quatro repetições de 10 sementes.

Para a avaliação dos substratos, seis repetições de 20 sementes foram semeadas em caixas de plástico (35x20x12cm) entre areia (média), vermiculita, solo (latossolo), serragem (Platymiscium trinitatis Benth.), resíduos triturados de açaí (endocarpo + semente), areia + vermiculita (1:1), areia + solo (latossolo) (1:1), areia + serragem (1:1) e areia + resíduos triturados de açaí (endocarpo + sementes) (1:1), todos umedecidos até $60 \%$ da capacidade de retenção em água destilada; as caixas permaneceram em temperatura ambiente $\left(25 \pm 3^{\circ} \mathrm{C}\right)$ com sombreamento de $50 \%$ por meio de tela sombrite, em casa de vegetação durante 20 dias.

Para a avaliação da profundidade de semeadura, seis repetições de 20 sementes foram semeadas em caixas de plástico, a 0, 1, 2 e 4cm de profundidade, entre areia umedecida com água destilada até $60 \%$ da capacidade de retenção, mantidas em temperatura ambiente $\left(25 \pm 3^{\circ} \mathrm{C}\right)$ e sombreamento de $50 \%$ por meio de tela sombrite, em casa de vegetação durante 30 dias.

Para a emergência das plântulas, o critério adotado foi o de plântula normal, de acordo com BRASIL (2009), e a porcentagem e a velocidade de emergência foram calculadas segundo BEWLEY \& BLACK (1994) e HONG et al. (2005), respectivamente.

O delineamento experimental foi inteiramente casualizado, sendo que, para a análise de variância, foi aplicado o Teste $\mathrm{F}$ e, quando significativo, as comparações entre as médias foram realizadas por meio do Teste de Tukey em nível de 5\% de probabilidade (SAS Institute, 2003), enquanto para a emergência em diferentes profundidades de semeadura, as equações de regressão foram calculadas de acordo PIMENTELGOMES (1987).

As maiores porcentagens de emergência de plântulas de ipê amarelo do cerrado foram observadas nos substratos areia, areia + vermiculita (1:1), vermiculita, areia + resíduos triturados de açaí (endocarpo + semente) (1:1) e areia + solo (latossolo) (1:1) (Tabela 1). Da mesma forma, a areia foi considerada um substrato adequado para a germinação de sementes de bignociáceas (BIANCHETTI et al., 1995; FOWLER et al., 1998; MACHADO et al., 2002; PACHECO et al., 2008). Todavia, de acordo com BOCCHESE et al. (2008), os solos mais argilosos e argilosos com matéria orgânica foram mais adequados para a germinação de sementes de ipê-roxo (Tabebuia heptaphylla (Vell.) Tol.).

Para ipê amarelo, a areia e a vermiculita estão entre os substratos que proporcionam maiores porcentagens de germinação de sementes (Tabela 1), no entanto, a vermiculita foi inadequada para a germinação de sementes de caixeta (Tabebuia cassinoides (Lam.) DC.) (BIANCHETTI et al., 1995), craibeira (Tabebuia aurea (Silva Manso) Benth. \& Hook. f. ex. S. Moore) (PACHECO et al., 2008) e ipêbranco (Tabebuia roseo-alba (Rdl.) Sandw.) (STOCKMAN et al., 2007).

Na semeadura entre areia, areia + vermiculita (1:1), vermiculita, areia + resíduos triturados de açaí (endocarpo + semente) (1:1) e areia + solo (latossolo) (1:1), foram observadas as maiores velocidades de emergência de plântulas de ipê amarelo do cerrado (Tabela 1). De forma semelhante, as sementes de ipêamarelo (MACHADO et al., 2002) e ipê-roxo (BOCCHESE et al., 2008) germinaram mais rapidamente em substratos arenosos. Entretanto, as sementes de bignoniáceas germinaram mais rapidamente em substrato papel (MACHADO et al., 2002; STOCKMAN et al., 2007; PACHECO et al., 2008).

A porcentagem de emergência de plântulas de ipê amarelo foi reduzida significativamente a partir de $2 \mathrm{~cm}$ de profundidade (Tabela 1 ), enquanto as 
Tabela 1 - Porcentagem (PE) e velocidade de emergência (VE) de plântulas de ipê amarelo (Tabebuia caraiba (Mart.) Bureau) em diferentes substratos e profundidades de semeadura.

\begin{tabular}{lll}
\hline Substrato & PE (\%) & VE \\
\hline Areia (A) & $83 \mathrm{a}$ & $1,21 \mathrm{a}$ \\
A + V (1:1) & $73 \mathrm{a}$ & $1,06 \mathrm{a}$ \\
Vermiculita (V) & $68 \mathrm{a}$ & $0,95 \mathrm{a}$ \\
A + C (1:1) & $68 \mathrm{a}$ & $1,00 \mathrm{a}$ \\
A + T (1:1) & $68 \mathrm{a}$ & $0,99 \mathrm{a}$ \\
solo (latossolo) (T) & $55 \mathrm{~b}$ & $0,78 \mathrm{~b}$ \\
resíduos triturados de açaí (endocarpo + semente) (C) & $47 \mathrm{~b}$ & $0,65 \mathrm{~b}$ \\
A + S (1:1) & $35 \mathrm{~b}$ & $0,48 \mathrm{c}$ \\
Serragem (S) & $30 \mathrm{~b}$ & $0,37 \mathrm{c}$ \\
CV (\%) & 23,52 & 25,31 \\
Teste F & $6,92^{* *}$ & $7,12^{* *}$ \\
Profundidade (cm) & PE (\%) & VE \\
0 & $66,7^{\mathrm{a}}$ & $1,14 \mathrm{a}$ \\
1 & $64,2^{\mathrm{a}}$ & $0,82 \mathrm{~b}$ \\
2 & $34,2 \mathrm{~b}$ & $0,31 \mathrm{c}$ \\
4 & $0,0 \mathrm{c}$ & $0,00 \mathrm{~d}$ \\
CV (\%) & 26,69 & 25,49 \\
Teste F & $48,21^{* *}$ & $74,55^{* *}$ \\
\hline
\end{tabular}

** Significativo a 1\% de probabilidade pelo Teste F. Médias seguidas de mesma letra nas colunas não diferem entre si pelo Teste de ScottKnot a 5\% de probabilidade.

plântulas de Aloysia gratissima (Gill. et Hook) Troncoso emergiram adequadamente na profundidade de em $1 \mathrm{~cm}$ em areia (34\%)(ROSA \& FERREIRA, 2001). A partir de $1 \mathrm{~cm}$ de profundidade, houve diminuição significativa na velocidade de emergência de plântulas de ipê amarelo (Tabela 1).

A porcentagem de emergência de plântulas de ipê amarelo foi linearmente nula a partir de 5,85cm de profundidade (Figura 1A), sendo que, a partir de $3,71 \mathrm{~cm}$, a velocidade de emergência de plântulas de ipê amarelo foi linearmente inviável (Figura 1B). Devido ao aumento da barreira física, NAPIER (1985) relatou que a semeadura muito profunda dificulta a emergência das plântulas e aumenta o período de suscetibilidade a patógenos.

A sequência dos substratos mais adequados para emergência de plântulas é: areia, vermiculita, areia + vermiculita (1:1), areia + solo (latossolo) (1:1) e areia + resíduos triturados de açaí (endocarpo + sementes) (1:1); As semeaduras superiores a $1 \mathrm{~cm}$ são inadequadas para a emergência de plântulas de ipê amarelo.

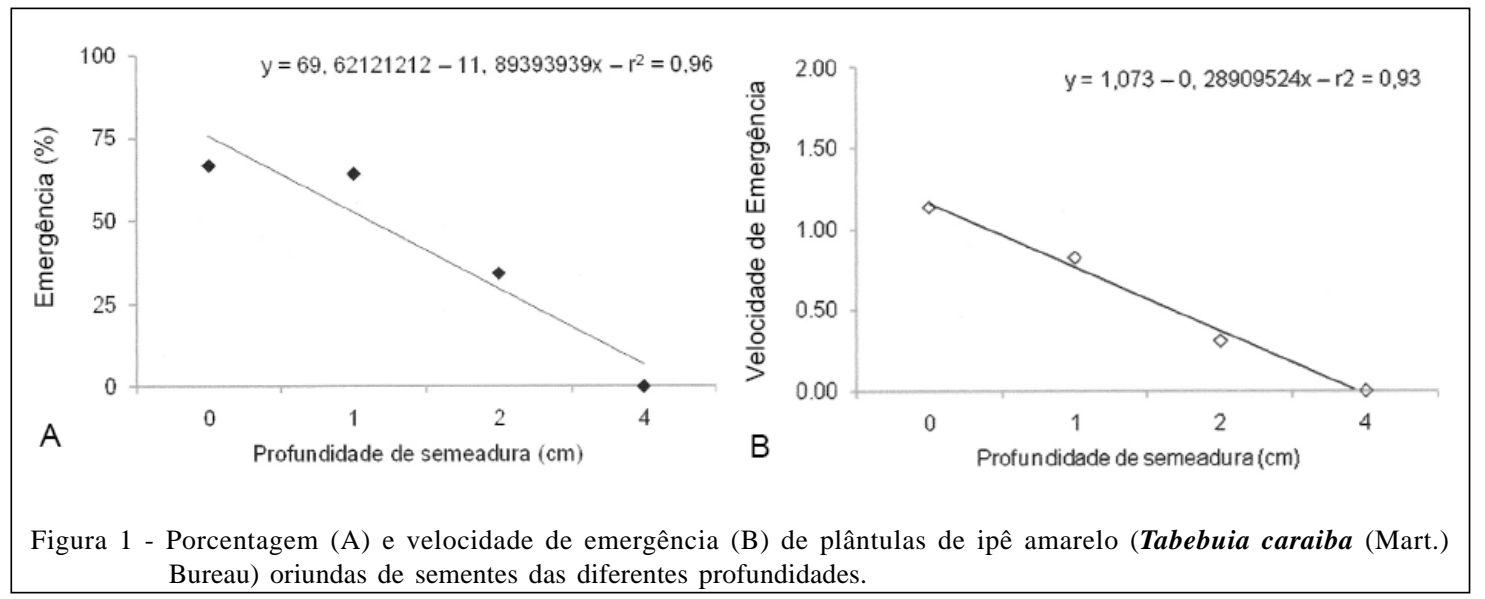

Ciência Rural, v.42, n.8, ago, 2012. 


\section{REFERÊNCIAS}

BEWLEY, J.D.; BLACK, M. Seeds: physiology of development and germination. New York: Plenum, 1994. 445p.

BIANCHETTI, A. et al. Substratos e temperaturas para a germinação de sementes de caixeta (Tabebuia cassinoides). Comunicado Técnico: EMBRAPA - Centro Nacional de Pesquisa Florestais, 1995. V.4, 2p. Disponível em: <http://www.cnpf.embrapa.br/ publica/comuntec/edicoes/com_tec04.pdf>. Acesso em: 27 out. 2011.

BOCCHESE, R.A. et al. Efeito de diferentes tipos de solos na germinação de sementes de Tabebuia heptaphylla, em casa telada. Cerne, v.14, n.1, p.62-67, 2008. Disponível em: <http:// redalyc.uaemex.mx/redalyc/html/744/74414108/74414108.html>. Acesso em: 27 out. 2011.

BRASIL. Ministério da Agricultura, Pecuária e Abastecimento. Regras para análises de sementes. Secretaria de Defesa Agropecuária. Brasília: MAPA/ACS, 2009. 395p. Disponível em: <http:// www.bs.cca.ufsc.br/publicacoes/regras\%20analise\%20sementes.pdf>. Acesso em: 27 out. 2011.

FOWLER, J.A.P. et al. Germinação e vigor de sementes de Tabebuia cassinoides (Lam.) DC. coletadas em diferentes caxetais do litoral paranaense. Comunicado Técnico: EMBRAPA - Centro Nacional de Pesquisa Florestais, 1998. V.25, 5p. Disponível em: <http://www.cnpf.embrapa.br/publica/comuntec/edicoes/ com_tec25.pdf $>$. Acesso em: 27 out. 2011.

HONG, T. D. et al. Survival and vigour of ultra-dry seeds after ten years of hermetic storage. Seed Science and Technology, v.33, n.2, p.449-460, 2005.

NASSIF, S.M.L. et al. Fatores externos (ambientais) que influenciam na germinação de sementes. Piracicaba: Informativo sementes (IPEF), 1998. Disponível em: <www.ipef.br/ tecsementes/germinacao.asp>. Acesso em: 27 out. 2011.

MACHADO, C.F. et al. Metodologia para a condução e teste de germinação em sementes de ipê-amarelo (Tabebuia serratifolia (Vahl)
Nicholson). Cerne, v.8, n.2, p.17-25, 2002. Disponível em: <http:/ /redalyc.uaemex.mx/redalyc/pdf/744/74480202.pdf>. Acesso em: 27 out. 2011.

MELO, J.T. et al. Coleta, propagação e desenvolvimento inicial de espécies do cerrado. In: SANO, S.M. et al. (Eds.). Cerrado: ambiente e flora. Embrapa Cerrados. Brasília: EMBRAPA Informação Tecnológica, 2008. 1.279p.

NAPIER, I. Tecnicas de viveros florestales con referencia especial a centroamerica. Costa Rica: Signa Tepec, Ed. Espemacifor, 1985. 274p.

PACHECO, M.V. et al. Germinação de sementes e crescimento inicial de plântulas de Tabebuia aurea (Silva Manso) Benth. \& Hook f. ex S. Moore. Ciência Florestal, v.18, n.2, p.143-150, 2008. Disponível em: <http://cascavel.ufsm.br/revistas/ojs-2.2.2/index.php/ cienciaflorestal/article/view/452/349>. Acesso em: 27 out. 2011.

PIMENTEL-GOMES, F. Curso de estatística experimental. São Paulo: Nobel, 1987. 467p.

ROSA, S.GT.; FERREIRA, A.G. Germinação de sementes de plantas medicinais lenhosas. Acta Botanica Brasilica, v.15, n.2, p.147154. 2001. Disponível em: <http://www.scielo.br/pdf/abb/v15n2/ 6819.pdf>. Acesso em: 27 out. 2011.

SAS Institute. SAS/STAT User's Guide. Version 9.1. Cary NC. 2003. 167p.

SOUZA, V.C.; LORENZI, H. Botânica sistemática: guia ilustrado para identificação das famílias de angiospermas da flora brasileira, baseado em APGII. Nova Odessa: Instituto Plantarum de Estudos da Flora, 2005. 650p.

STOCKMAN, A.L. et al. Sementes de ipê-branco (Tabebuia roseoalba (Ridl.) Sand. - Bignoniaceae): temperatura e substrato para o teste de germinação. Revista Brasileira de Sementes, v.29, n.3, p.139-143, 2007. Disponível em: <http://www.scielo.br/pdf/rbs/ v29n3/a16v29n3.pdf>. Acesso em: 27 out. 2011. 